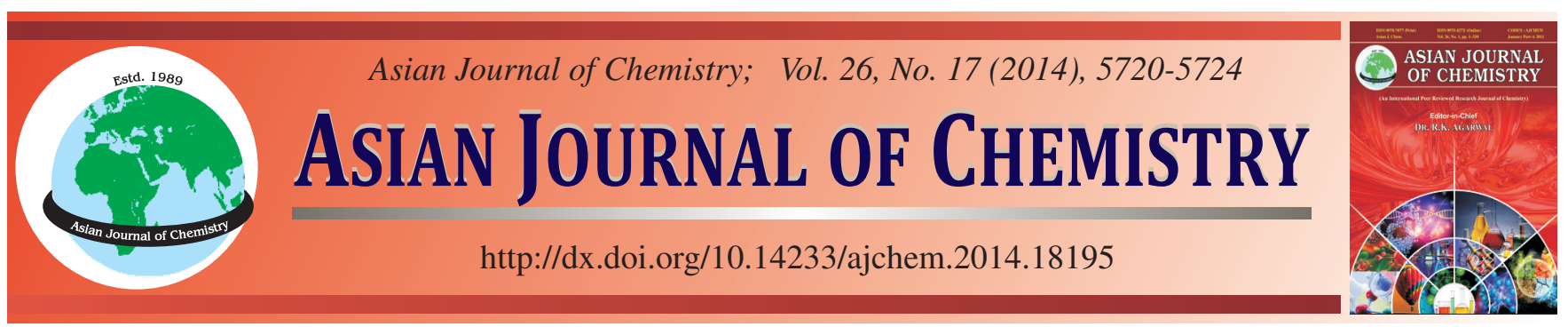

\title{
Fabrication and Upsetting of Al6061 Aluminum Metal Matrix Composite with Carbon Nanotube Reinforcement $\dagger$
}

\author{
Chang Ho LeE ${ }^{1}$ and Chung Gil KanG ${ }^{2, *}$
}

${ }^{1}$ Department of Precision Mechanical Engineering, Pusan National University, Busan, 609-735, Republic of Korea

${ }^{2}$ Department of Mechanical Engineering, Pusan National University, Busan,609-735, Republic of Korea

*Corresponding author: Fax: +82 51 5181456; Tel: +82 51 5102335; E-mail: cgkang@pusan.ac.kr

\begin{abstract}
This study aims to examine the fabrication and upsetting of Al6061 alloy reinforced by carbon nanotubes. The composite material that combines Al6061 powder (5-30 $\mu \mathrm{m}$ ) and multiwall carbon nanotubes (MWCNTs) after the dispersion process goes through the compaction at room temperature and sintering to fabricate the billet. In addition, the upsetting process is conducted to evaluate the mechanical properties of fabricated composite specimens and improve the relative density. As for the composite, MWCNTs of 1 and $3 \%$ volume fraction are fabricated to compare with Al6061alloy. The billet is fabricated at room temperature at the pressure level of 300,450 and 600 $\mathrm{MPa}$. It also goes through the sintering process $\left(580,600,620^{\circ} \mathrm{C}\right)$ in an argon gas atmosphere. CNT-Al6061 composite shows a lower level of relative density than that of A16061 alloy in the same condition. To improve the relative density of the complex material, the upsetting process is added. The fabrication and characteristics of CNTs-Al6061 composite are developed through the compaction at room temperature and through sintering and upsetting, with the mechanical properties being superior to those of Al6061 alloy. As a result, the mechanical properties of the composite increase in proportion to the compaction pressure and sintering temperature. As the amount of MWCNTs increase, however, elongation decreases.
\end{abstract}

Keywords: Carbon nanotubes, Compaction at room temperature, Sintering, Upsetting, Metal matrix composite.

\section{INTRODUCTION}

After the discovery of carbon nanotubes by Iijima ${ }^{1}$, a number of researches have been conducted for their application. Carbon nanotubes feature the initial elastic modulus up to $1000 \mathrm{GPa}$ and strength up to $100 \mathrm{GPa}$. The heat conductivity $^{2-6}$ reaches $6000 \mathrm{Wm}^{-1} \mathrm{~K}^{-1}$.

Currently, the fabrication of Metal Matrix Composites with carbon nanotubes is drawing attention for its high mechanical properties. In the case of carbon nanotubes-metal composite, the fabrication is based on the powder processing for even dispersion. In general, carbon nanotubes and metal powder are mechanically alloyed through the ball-milling process ${ }^{7}$.

The most important part of CNT-metal composite is to improve the density of the dispersed composite in the process of compaction and sintering. With the powder mixed through the ball-milling, CNT-metal composite is fabricated in the hot compaction or extrusion process. Wu et al.$^{8}$ conducted the hot compaction experiment of CNTs-Al6061 composites in application of the semi-solid powder processing (SPP). The composite was fabricated in a way that the relative density of the composite increased up to $97 \%$ at $620^{\circ} \mathrm{C}$ through semi-solid powder processing and that the hardness increased $42.3 \%$ higher than that of common Al6061 alloys. Hansang et al. ${ }^{9}$ conducted a study on the CNTs-Al composite through the hot extrusion process. The completely densified Al-1 vol \% CNTs were fabricated through the hot extrusion process, but $\mathrm{Al}_{4} \mathrm{C}_{3}$ was found due to the high temperature. The mechanical properties of the composite may decrease due to oxidation. In addition to such oxidation problems, a number of studies focus on the fabrication of CNTs-metal composites. Hence, after the fabrication of composites, there should be a study on such secondary forming methods as upsetting, rolling and extrusion after fabrication to increase the relative density and mechanical properties.

Accordingly, this study aims to fabricate CNTs-A16061 composites with various conditions and to improve the relative density and mechanical properties through the upsetting-based secondary forming. In the experiment, oxidation was prevented through the sintering in the tube furnace filled with Ar gas and 
during the compaction process at room temperature. The changes in the density and mechanical properties before and after the composite upsetting were comparatively observed.

\section{EXPERIMENTAL}

This study is to fabricate Metal Matrix Composites. MWCNTs were used for reinforcement, with Al6061 alloy powder as the matrix. In the two experiments of Hansang et al., it turned out that the tensile strength was stronger when $1 \mathrm{vol} \%$ CNT was added to aluminum than when 5 vol \% CNT was added $^{9,10}$. In this study, 1 and 3 vol \% CNT fractions were used. In addition, Al6061 was used in the experiment since it enhanced the aluminum fraction and was widely used in the engineering circles. For comparison, Al6061 alloy with no reinforcement added was fabricated. The properties of A16061 alloy and CNTs are presented in Table-1. The CNTs and Al6061 alloy powder were mechanically alloyed through the ball-milling process. The schematic diagram of CNT-Al6061 powder formation that was mechanically alloyed is presented in Fig. 1. The density when the carbon nanotubes was dispersed and mixed with 1 and 3 vol \% Al6061 alloy powder was 2.69 and $2.66 \mathrm{~g} / \mathrm{cm}^{3}$, respectively.

\begin{tabular}{lcccc}
\multicolumn{6}{c}{ TABLE-1 } \\
\multicolumn{3}{c}{ PROPERTIES OF Al6061 ALLOY AND CNTS (ACN, KOREA) } \\
\hline \multirow{3}{*}{ Material } & $\begin{array}{c}\text { Density } \\
\left(\mathrm{g} / \mathrm{cm}^{3}\right)\end{array}$ & $\begin{array}{c}\text { Mean } \\
\text { diameter } \\
(\mu \mathrm{m})\end{array}$ & $\begin{array}{c}\text { Tensile } \\
\text { strength } \\
(\mathrm{GPa})\end{array}$ & $\begin{array}{c}\text { Young's } \\
\text { modulus } \\
(\mathrm{GPa})\end{array}$ \\
\hline Al6061 alloy & 2.70 & $5-30$ & 0.120 & 68.9 \\
CNTs & $\sim 1.34$ & 0.02 & 100 & 1200 \\
\hline
\end{tabular}

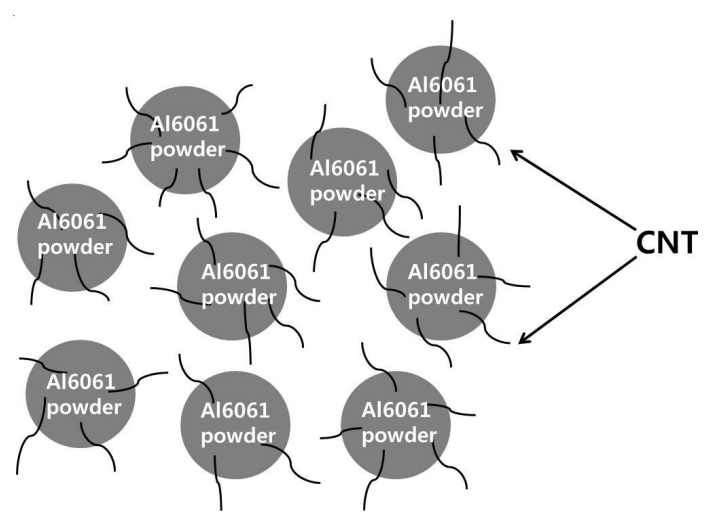

Fig. 1. Schematic of CNT-A16061 powder

Compaction at room temperature: For the compaction of evenly mixed Al6061 alloy and MWCNTs powder, dies were produced. The Rockwell hardness of the dies was HRC 60 or higher with the ASTM D2 steel used. At room temperature, compaction of the 1, 3 vol \% CNTs-Al6061 composite powder and Al6061 alloy powder was performed with the dies. The compaction at room temperature was about ASTM B925. First of all, the pre-compaction at the pressure of $35 \mathrm{MPa}$ was followed by the compaction in the condition of 300, 450 and $600 \mathrm{MPa}$. A rate of compaction pressure is set to $5.0 \mathrm{MPa} / \mathrm{s}$. To calculate the exact relative density of the specimen, the pressure was released immediately after the target pressure was reached in the way specified in ASTM B331. The graphite lubricant was used for the sticking prevention and lubrication of dies. After compaction, the green density and relative density were measured according to Archimedes' principlein reference to ASTM B962-13 to confirm the compaction rate of the produced billet.

Sintering: Sintering was conducted about ASTM B925. To prevent the oxidation of CNTs and Al6061 powder, sintering was performed within the argon gastube furnace. As for sintering temperature setting, the 6061 solid fraction referred by Jin et al..$^{11}$ at $600{ }^{\circ} \mathrm{C}$ at which Al6061alloy starts to exist in liquid form was set as the standard temperature. Also $580^{\circ} \mathrm{C}$ was set to minimum temperature. Al6061 at $580{ }^{\circ} \mathrm{C}$ contains only solid phase. In addition, the maximum sintering temperature was set to $620{ }^{\circ} \mathrm{C}$, when the liquid fraction of Al6061 alloy was $20 \%$ or lower, to maintain the formation of billets. Each sintering temperature, holding time and heating/cooling rate was fixed to $2 \mathrm{~h}$ and $5^{\circ} \mathrm{C} / \mathrm{min}$ each.

Upsetting: After the compaction and sintering processes, the billet was processed as a cylindrical specimen of $12.7 \mathrm{~mm}$ in diameter and $19.0 \mathrm{~mm}$ in length about ASTM D695. The length/diameter ratio of the specimen was 1.5 . The compression test was conducted with the strain rate set to $0.05 / \mathrm{min}$ in application of the MTS testing machine (MTS 810).

In the compaction experiments, the strain limit right before the fracture was determined and the upsetting process was implemented through the secondary forming that ended right before the fracture. The strain rate for upsetting was same with compaction test. Additionally, the changes in the density before and after upsetting were measured according to Archimedes' principle. Changes in Vickers hardness were measured with the load set to $300 \mathrm{~g}_{\mathrm{F}}$. The changes in the microstructure before and after upsetting were measured by means of an optical microscope (Olympus, Japan).

\section{RESULTS AND DISCUSSION}

Compaction characteristics: Changes in the green density and relative density depending on the compaction at room temperature are presented in Fig. 2. For Al6061 alloy, Showaiter et al., analyzed the green density ${ }^{12}$. In this experiment as well, the same effect was observed as with Al6061. As for 1, 3 vol \% CNTs-Al6061 composites, the relative density was low at the same pressure in comparison with Al6061 alloy. The relative density of the composite drastically increased at $600 \mathrm{MPa}$. In Fig. 2, the relative density of 1, 3 vol \% CNTs-Al6061 at 600 MPa was 84.0 and $83.1 \%$, respectively, which was lower than $96.3 \%$ that of Al6061alloy. This result indicates that the adhesion between powders requires high pressure in the case of CNTs-Al6061 probably because of the high strength of CNTs. As to CNTs-Al6061 composite, the deviation of the density increased in inverse proportion to the pressure.

Mechanical properties after compaction and sintering: First of all, sintering was followed by a compressive strength test in the condition specified (see Sintering section). The compressive strength was measured up to the point of specimen fracture. Fig. 3 shows the stress-strain curve of Al6061 alloy and 1,3 vol \% CNTs-Al6061 specimen produced at the sintering temperature of $620^{\circ} \mathrm{C}$ and the compaction at room temperature of $600 \mathrm{MPa}$. The fractures of the 1, $3 \mathrm{vol} \%$ CNTs composites and Al6061alloy occurred around $0.48,0.41$ and 0.28 of each 


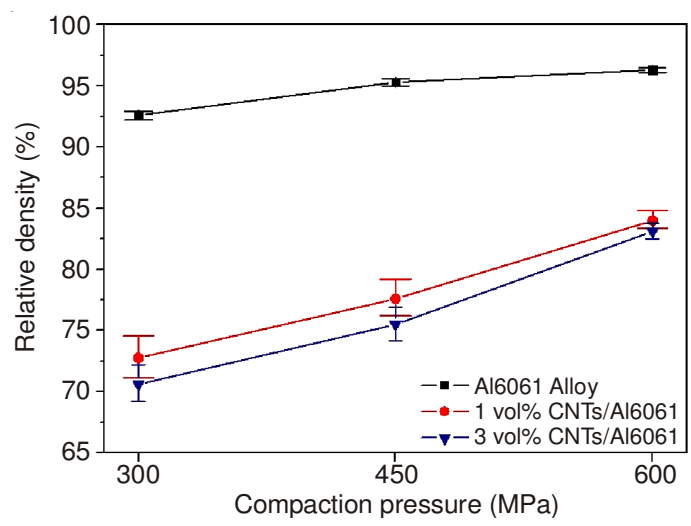

(a) Relative density of materials depending on the pressure

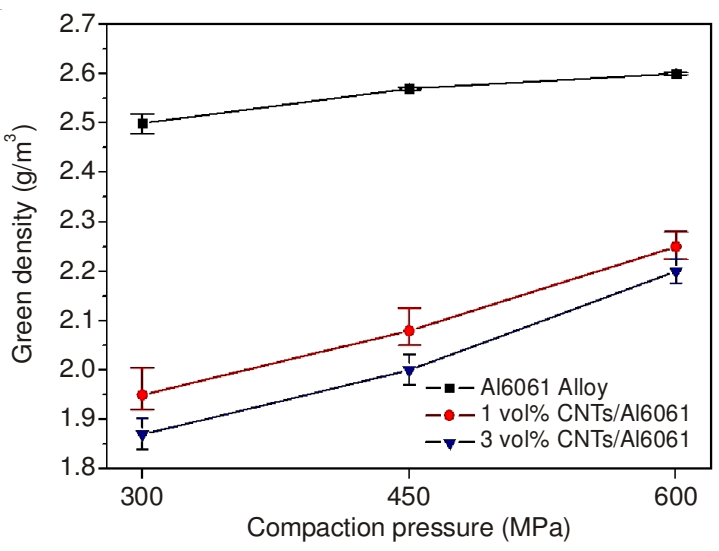

(b) Green density of materials depending on the pressure

Fig. 2. Changes in relative density and green density of each material depending on the pressure

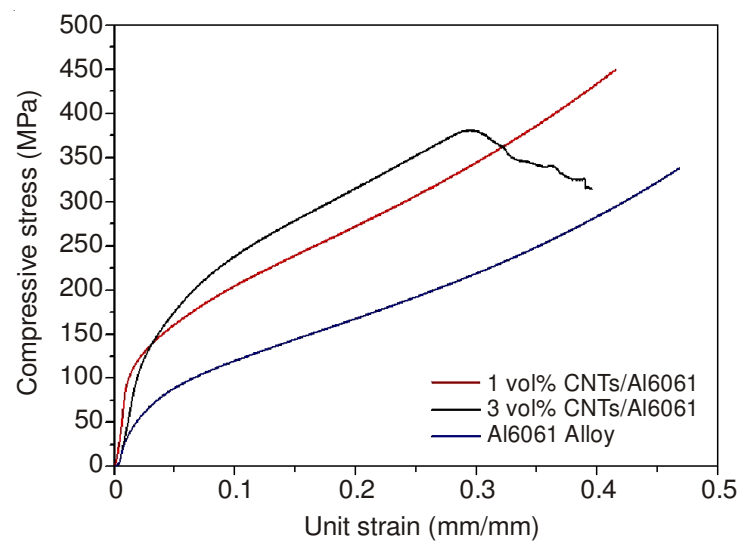

Fig. 3. Compressive stress-strain curve of each material (compaction pressure: $600 \mathrm{MPa}$; sintering temperature: $620^{\circ} \mathrm{C}$ )

strain, which indicated that as the content of CNTs increased, the level of elongation decreased accordingly. 3 vol \% CNTsAl6061 specimen was of brittle material whose compaction stress would decrease after fracture.

As to 1 vol \% of CNTs-Al6061 and Al6061 alloy, the compaction stress continued to increase even after fracture; thus, there was no peak compressive stress. About 1 vol \% CNTs-Al6061 specifically, the elongation slightly decreased in comparison to Al6061alloy, but the strength increased to a large extent.

Changes in the compressive strength depending on the compaction pressure at the same sintering temperature of $620^{\circ} \mathrm{C}$ are presented in Fig. 4. The compressive strength of the composites at 300 and $450 \mathrm{MPa}$ indicates that the value is lower than that of Al6061 alloy. The lower level of relative density indicates the existence of higher porosity in the specimen. It is thought that upon diffusion between powders in sintering, many porosities decrease compressive strength. At $600 \mathrm{MPa}$ where the relative density drastically increases, the compressive strength is higher than that of Al6061 alloy.

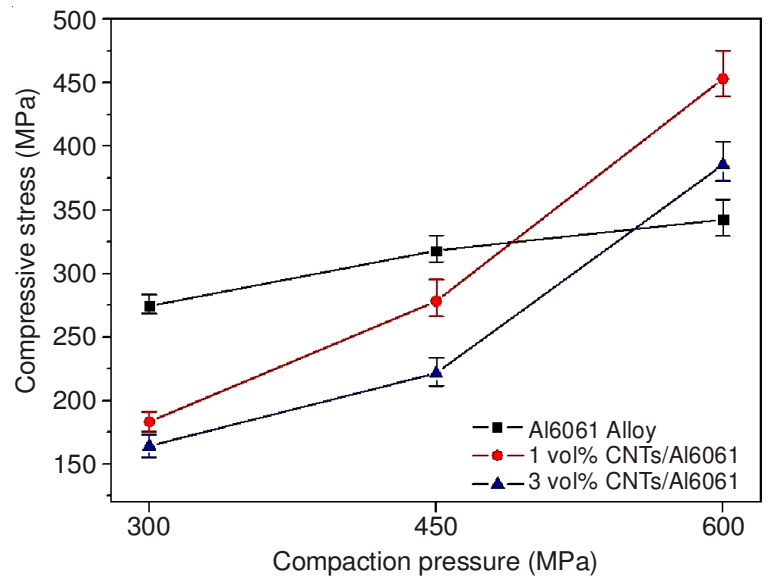

Fig. 4. Changes in compressive stress of each material depending on the compaction pressure (sintering temperature: $620{ }^{\circ} \mathrm{C}$ )

At the same pressure of $600 \mathrm{MPa}$, changes in the compressive strength depending on the sintering temperature are presented in Fig. 5. In the case of Al6061 alloy, the strength slightly increased depending on the temperature, but the compressive strength of CNTs-Al6061 specimen drastically increased at $620^{\circ} \mathrm{C}$. This result may come from increase of the liquid fraction of Al6061 alloy. The liquid fraction drastically increases from $\mathrm{ca} .5 \%$ at $600{ }^{\circ} \mathrm{C}$ in the coexistence section to $17 \%$ at $620^{\circ} \mathrm{C}$, which is thought to result from the sufficient bonding between the carbon nanotubes and A16061. In contrast, Al6061 involves some degree of strength reduction at $620^{\circ} \mathrm{C}$ or higher, which is thought to result from the structural recrystallization and grain coarsening.

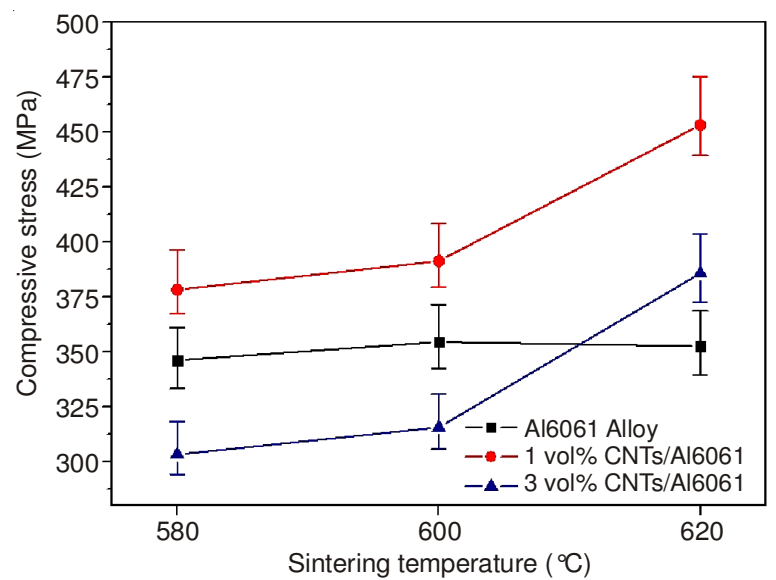

Fig. 5. Changes in compressive stress of each material depending on the sintering temperature (compaction pressure: $620^{\circ} \mathrm{C}$ )

The level of Vickers hardness of the cross-section both in the direction of and in the vertical direction of the compaction 
of the fabricated specimens before upsetting was also measured at $600 \mathrm{MPa}$ and $620^{\circ} \mathrm{C}$ and the result is presented in Fig. 6. As to the composite, the level of Vickers hardness of the specimen was low as the relative density was low. The level of hardness was the highest in the case of $1 \mathrm{vol} \%$ CNT composite in proportion to the compressive stress. In contrast, Al6061 alloy involved the lowest level of hardness. In addition to the measurement of Vickers hardness, the micro structure images of the cross-section in the direction of and in a vertical direction of the compaction are presented in Fig. 7. In the case of the composites, the porosities were bigger and in a larger number than Al6061 due to the low level of relative density. It is predicted that the large number of porosities would affect the hardness and strength of composites negatively.

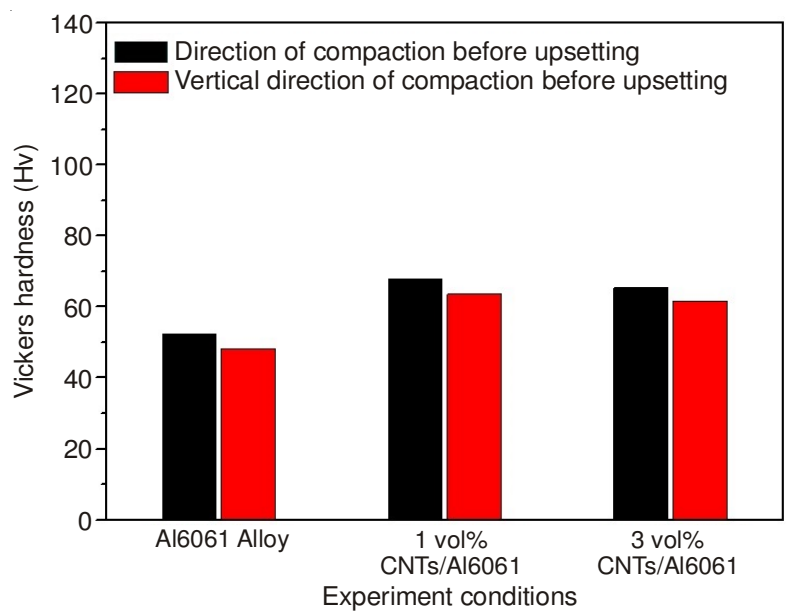

Fig. 6. Vickers hardness of the cross-section in the direction of and in vertical direction of compaction Before upsetting (compaction pressure: $600 \mathrm{MPa}$; sintering temperature: $620^{\circ} \mathrm{C}$ )

Changes in mechanical properties after upsetting: As shown in Fig. 3, 1, 3 vol \% CNTs specimen and Al6061 alloy specimen produced at $600 \mathrm{MPa}$ and $620^{\circ} \mathrm{C}$ and upsetting were implemented with the strain values to $0.37,0.25$ and 0.45 before each fracture. The changes in density before and after upsetting are presented in Fig. 8. In the case of Al6061which had a high level of relative density, the change in density after compaction was $0.8 \%$, but the relative density of CNTs' composite specimens drastically increased to 12.3 and $9.3 \%$ each. This indicates that, upon compaction at room temperature, it requires a high pressure to increase the relative density but it is relatively easy to increase the density by upsetting the pressure lower than the compaction pressure after fabrication through the compaction and sintering processes. The level of Vickers hardness of materials after upsetting is presented in Fig. 9. After upsetting, the hardness of CNT-A16061 composite significantly increased in comparison with Al6061 alloy because upsetting as well as the larger number of dislocations after the work hardening increased the density relatively. The large increase of the relative density indicates the reduction of the area of specimen porosities. This is also seen in the microstructure image (Fig. 10). The microstructure after upsetting shows that the area of porosities drastically decreased. In addition, the structural image of the cross-section after upsetting shows that the compaction of the crack in vertical direction of upsetting resulted in a lamination.
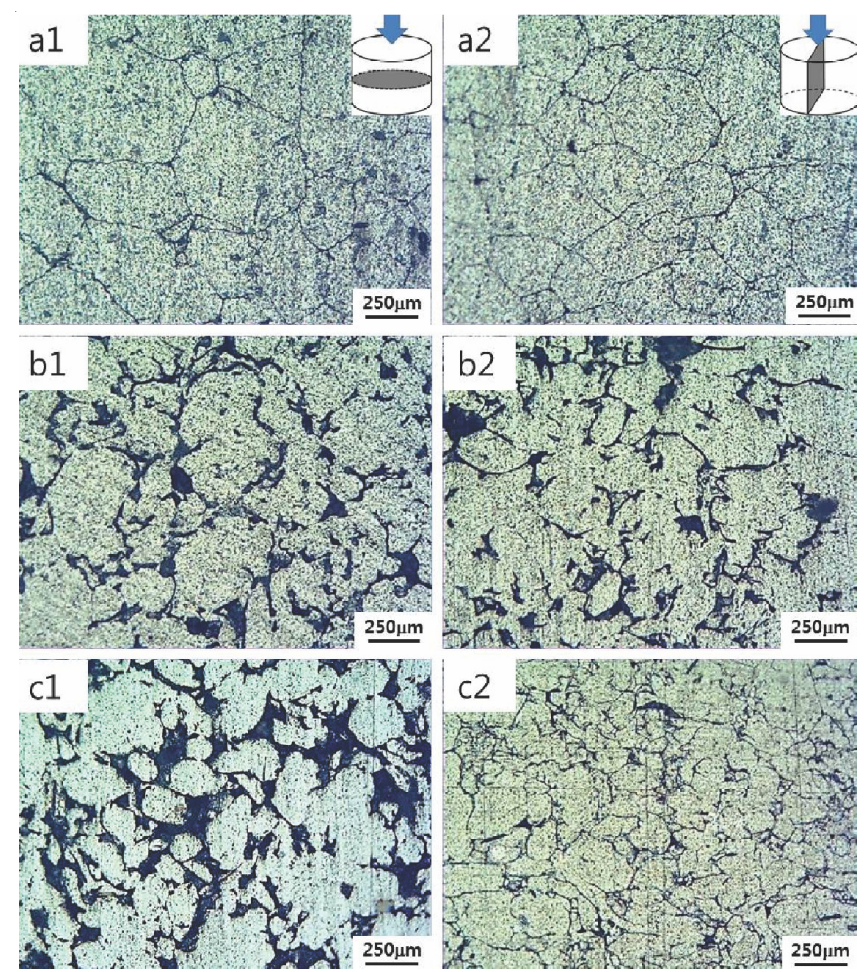

Fig. 7. Microstructures of cross-sectionin the direction of and in vertical direction of compaction before Upsetting(compaction pressure: 600 $\mathrm{MPa}$; sintering temperature: $620{ }^{\circ} \mathrm{C}$ ). (a1) Cross-section in the vertical direction of Al6061 Al6061 compaction. (a2) Cross-section in the direction of Al6061 compaction. (b1) Cross-section in the vertical direction of $1 \mathrm{vol} \%$ CNTs Al6061 compaction. (b2) Crosssection in the direction of 1 vol \% CNTs Al6061 compaction. (c1) Cross-section in the vertical direction of 3vol\% CNTs Al6061 compaction. (c2) Cross-section in the direction of 3 vol \% CNTs Al6061 compaction

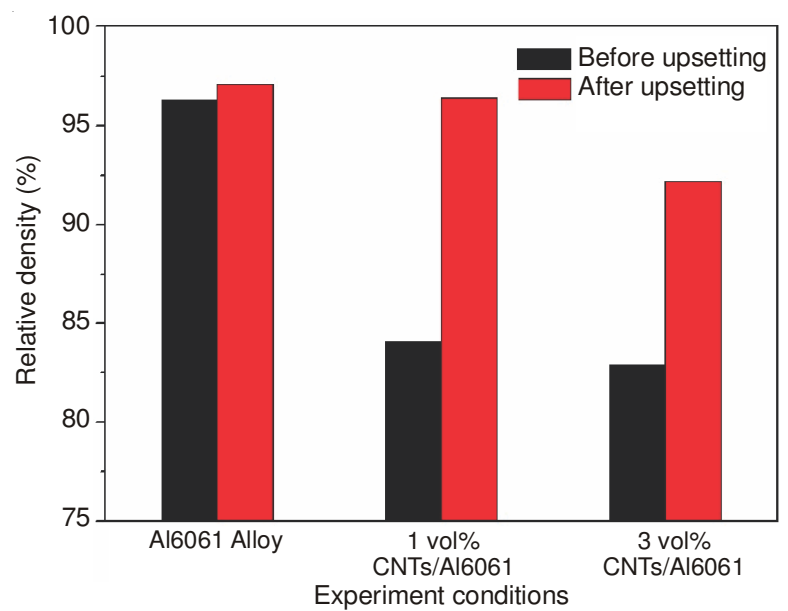

Fig. 8. Changes in density before and after the upsetting of each material (compaction pressure: $600 \mathrm{MPa}$; sintering temperature: $620^{\circ} \mathrm{C}$ )

\section{Conclusion}

In this study, CNTs-A16061 composite is subjected to the compaction, sintering and fabrication, which was followed by the secondary processing of upsetting. With different compaction pressure levels and sintering temperature conditions in the experiment, the composite fabrication was successfully implemented in the compaction test with a higher level of strength than the existing Al6061 alloy. Additionally, the relative 


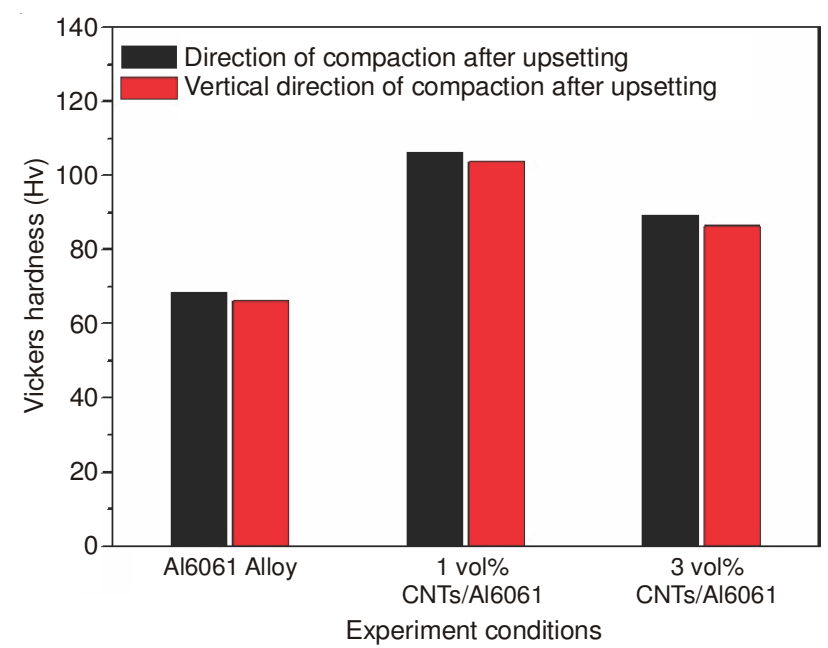

Fig. 9. Vickers hardness of cross-sections in the direction of and in vertical direction of compaction after upsetting(compaction pressure: 600 $\mathrm{MPa}$; sintering temperature: $620^{\circ} \mathrm{C}$ )
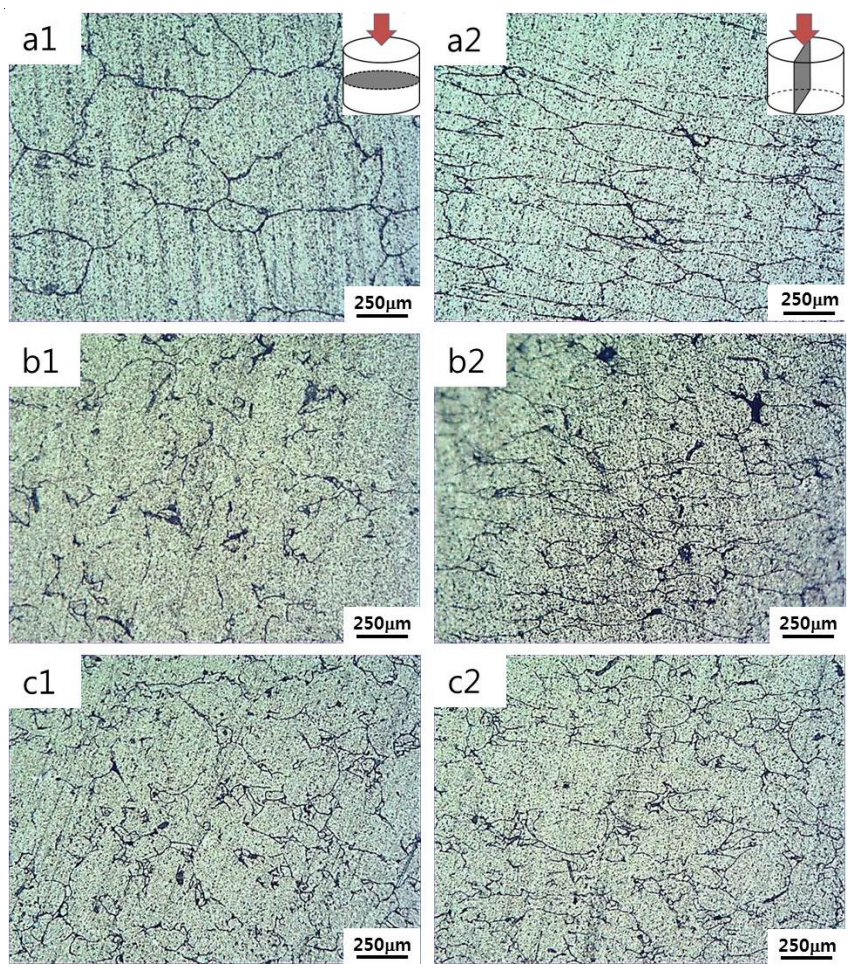

Fig. 10. Microstructures of cross-section in the direction of and in vertical direction of compaction after upsetting (compaction pressure: $600 \mathrm{MPa}$; sintering temperature: $620^{\circ} \mathrm{C}$ ). (a1) Cross-section in the vertical direction of A16061 Al6061 compaction after upsetting. (a2) Cross-section in the direction of Al6061 compaction after upsetting. (b1) Cross-section in the vertical direction of $1 \mathrm{vol} \% \mathrm{CNTs}$ Al6061 compaction after upsetting. (b2) Cross-section in the direction of 1 vol \% CNTs Al6061 compaction after upsetting. (c1) Cross-section in the vertical direction of 3 vol \% CNTs Al6061 compaction after upsetting. (c2) Cross-section in the direction of 3 vol \% CNTs Al6061 compaction after upsetting density and hardness of materials were enhanced through upsetting. As to changes in the green density depending on the compaction pressure and the strength depending on the sintering temperature, more specific follow-up researches are necessary. Based on the experiment results, this study has come to the following conclusions: In a compaction at room temperature, CNTs-A16061 composite involved a lower level of relative density than the existing Al6061 at the same pressure due to the high strength of CNTs. In the lower level of relative density, the compressive strength was lower than that of Al6061. With the sintering temperature set to $620^{\circ} \mathrm{C}$, the 1,3 vol \% CNT-Al6061 composites of $85 \%$ relative density involved a higher level of compressive strength than Al6061 alloy. As the sintering temperature increased, the strength of the composites increased accordingly. At $600{ }^{\circ} \mathrm{C}$ or higher especially, the increase of the liquid fraction contributed to the sufficient bonding between the carbon nanotubes and Al6061 and to better strength, as well. As the volume fraction of the carbon nanotubes increased, the elongation decreased accordingly and the elongation of the 1 vol $\%$ carbon nanotube composite decreased as much as $15 \%$ in comparison with the existing Al6061 while the compressive strength increased about $33 \%$ and the hardness to a maximum of $55 \%$. The secondary upsetting proved to enhance the relative density of CNTsAl6061 composite with a lower level of relative density at lower pressure than that in compaction at room temperature. The increase of relative density resulted in a higher level of hardness than that of Al6061 with the same upsetting applied condition.

\section{ACKNOWLEDGEMENTS}

This work was supported by Basic Science Research Program through the National Research Foundation of Korea (NRF) funded by the Ministry of Science, ICT and Future Planning (2013R1A1A2020735).

\section{REFERENCES}

1. S. Iljima, Nature, 354, 56 (1991).

2. M.M.J. Treacy, T.W. Ebbesen and J.M. Gibson, Nature, 381, 678 (1996).

3. A. Krishnan, E. Dujardin, T.W. Ebbesen, P.N. Yianilos and M.M.J. Treacy, Phys. Rev. B, 58B, 14013 (1998).

4. E.W. Wong, P.E. Sheehan and C.M. Lieber, Science, 277, 1971 (1997).

5. M.F. Yu, B.S. Files, S. Arepalli and R.S. Ruoff, Phys. Rev. Lett., 84, $5552(2000)$

6. M.F. Yu, O. Laurie, M.J. Dyer, K. Moloni, T.F. Kelly and R.S. Ruoff, Science, 287, 637 (2000).

7. A. Esawi and K. Morsi, Composites Part A, 38, 646 (2007).

8. Y. Wu, G.Y. Kim and A.M. Russel, J. Mater. Process. Technol., 211, 1341 (2011).

9. H.S. Kwon and M. Leparoux, Nanotochnology, 23, 415701 (2012).

10. H. Kwon, M. Estili, K. Takagi, T. Miyazaki and A. Kawasaki, Carbon, 47, 570 (2009).

11. C.K. Jin, Fuel Cells, 00, 201300137 (2013).

12. N. Showaiter and M. Youseffi, Mater. Design, 29, 752 (2008). 